
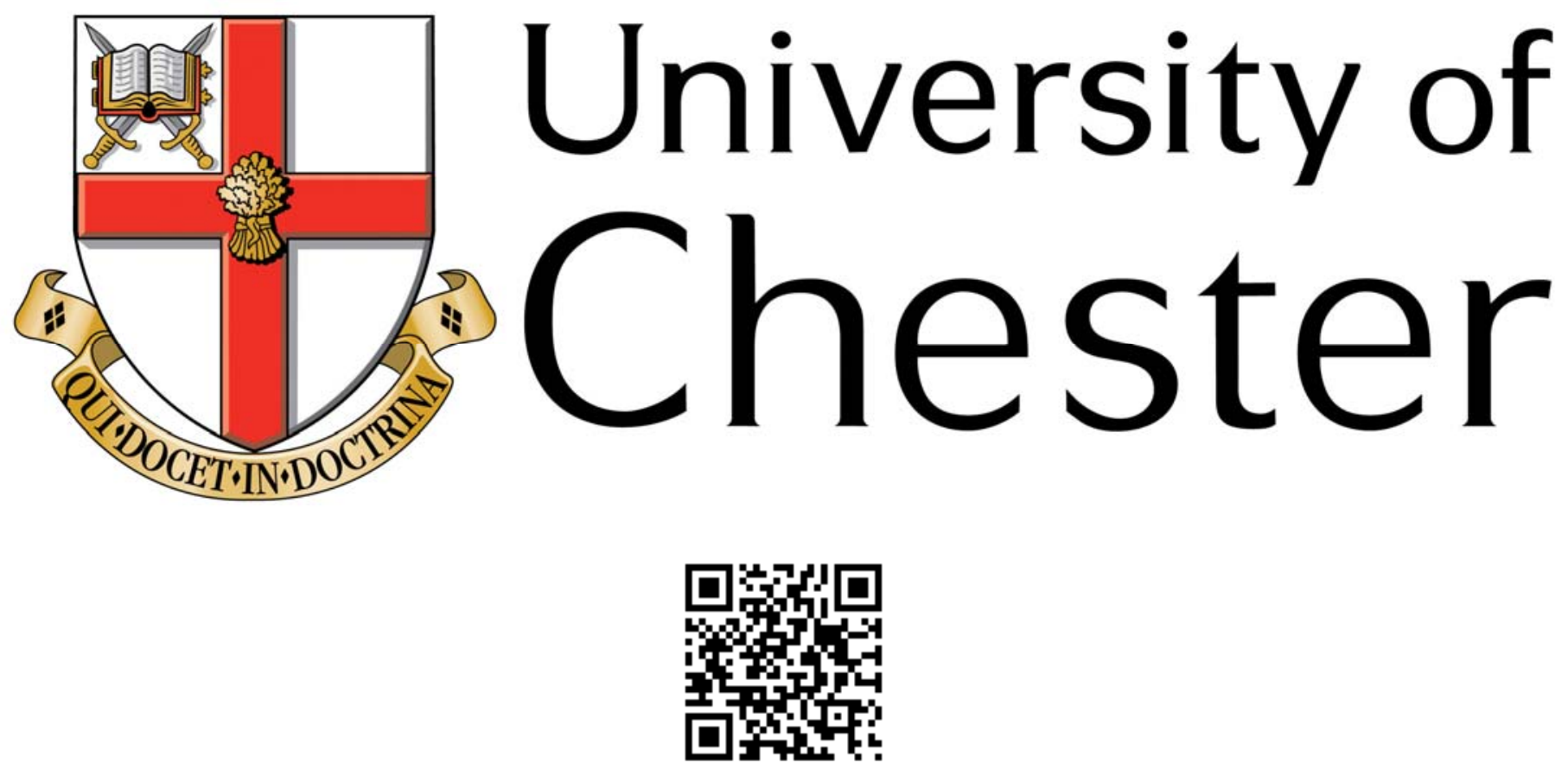

This work has been submitted to ChesterRep - the University of Chester's online research repository

\title{
http://chesterrep.openrepository.com
}

Author(s): Julie-Anne Regan

Title: The role obligations of learners and lecturers in higher education

Date: 2012

Originally published in: Journal of Philosophy of Education

Example citation: Regan, J-A. (2012). The role obligations of learners and lecturers in higher education. Journal of Philosophy of Education, 46(1), 14-28. doi: http://dx.doi.org/10.1111/j.1467-9752.2011.00834.x

Version of item: Author's post-print

Available at: http://hdl.handle.net/10034/326190 


\section{Title: The Role Obligations of Learners and Lecturers in Higher Education}

Author: Dr Julie-Anne Regan

Title: Academic Development Advisor

Department: Learning and Teaching Institute

Institution: University of Chester

Contact email: j.regan@chester.ac.uk

Contact Address: University of Chester

Parkgate Road

Chester

Cheshire

UK

$\mathrm{CH} 14 \mathrm{BJ}$

Contact telephone: 01244511947

Acknowledgements: To Dr Ruth Healey whose own reflections inspired me to explore this issue further. Also, to Mrs Jane Thomas for her assistance in proof reading and editing. 


\section{Abstract}

The current discussion of consumerism in higher education focuses largely on what the providers are obliged to do for the consumers, fuelled by the rising tuition fees. This framework does not always sit comfortably with lecturers in the context of a learning and teaching relationship, as it appears to ignore the reciprocal obligations lecturers and learners have to one another. The purpose of this paper is to offer an alternative view of what lecturers and learners are obliged to do in the learning and teaching relationship, if learning is to be effective.

The claims made in this paper are as follows:

- In higher education, both learners and lecturers have moral role obligations;

- These moral role obligations are derived from the functions of the roles being voluntarily undertaken by each party;

- Therefore, by ascertaining the functions of a learner and of a lecturer, both a descriptive purpose and a normative purpose will be revealed for each;

- Using moral role obligations as a basis for the student/lecturer relationship offers a less contentious alternative to the consumerist model.

This paper demonstrates, using Aristotle's function argument, that defining the function of an entity (in this case a role), has both a descriptive and normative purpose. It then briefly outlines possible definitions for the roles of learner and lecturer in higher education. Having made a claim (albeit a tentative one) to define the functions of learner and lecturer, recommendations are made on how these role obligations can be utilised to create an effective learning relationship. 


\section{Introduction}

There has been a good deal of discussion in the literature about the consumerist culture developing in the UK higher education (HE) system since the introduction of 'top-up' fees in September 2006 (for example Evans 2007, Jones 2010). With tuition fees set to increase significantly, this debate is unlikely to diminish in the near future. Authors, such as Evans (2007) claim the impact of consumer power, as a consequence of the National Student Survey and league tables, has been felt across the sector. Unlike in many other countries, where learners have long occupied the role of paying customers, this is a new phenomenon in the UK, which has been greeted with discomfort by many. Ramsden (2008), whilst Chief Executive of the Higher Education Academy, suggested he would rather students were viewed as partners in the learning process, than paying customers.

Unlike Jones (2010), who suggests that the sector needs to "engage with the notion of student as customer" (p44) in order to meet their expectations, I am offering an alternative view which recognises that both the learner and lecturers have moral obligations to one another. In this paper I want to focus on the role obligations of two of the stakeholders involved in the higher education experience, namely, those of the learner ${ }^{1}$ and the lecturer. Whilst the sector may need to engage with the consumer model at institution/customer level, I will argue that this is not appropriate in the pedagogic relationship between lecturer and learner.

The claims made in this paper are as follows:

- In higher education, both learners and lecturers have moral role obligations;

- These moral role obligations are derived from the functions of the roles being voluntarily undertaken by each party;

\footnotetext{
${ }^{1}$ For the purpose of this paper, I will use the term learner as a generic term for individuals paying for higher education.
} 
- Therefore, by ascertaining the functions of a learner and of a lecturer, both a descriptive purpose and a normative purpose will be revealed for each;

- Using moral role obligations as a basis for the student/lecturer relationship offers a less contentious alternative to the consumerist model.

I will first examine the concept of moral role obligations and establish that these are ontologically linked to the function of the role that each party undertakes. I will demonstrate, using Aristotle's function argument, that defining the function of an entity (in this case a role), has both a descriptive and normative purpose. I will then briefly outline possible definitions for the roles of learner and lecturer in higher education. Having made a claim (albeit a tentative one) to define the functions of learner and lecturer, I will discuss the implications of my argument for lecturers in higher education.

It is important to point out that this paper does not offer a concept analysis of a consumerist model of higher education. I will briefly outline some common views of why this concept might not provide the most positive foundation for the relationship between lecturers and their learners. It is also important to stress that this paper is only concerned with moral role obligations, rather than legal role obligations ${ }^{2}$. My concern is not with what both stakeholders must do in order to fulfil their legal obligations; rather what each one ought to do if they occupy those roles.

Because I am making a claim that the moral role obligations are derived from the function of an entity ${ }^{3}$, most of this paper comprises defending that claim by philosophical argument. Likewise, as I have modified an existing concept of moral role obligations (Hardimon 1994) and made a direct link to Aristotle's function

\footnotetext{
${ }^{2}$ Please see, for example, Melear (2003) for a comprehensive review of legal role obligations.

${ }^{3}$ By which, I refer to the 'function' of an entity in Aristotelian terms
} 
argument $^{4}$, I have focussed on defending that claim rather than comparing and contrasting various views of moral role obligations. Finally, I should like to recognise that the role of lecturer, and that of student, is wider than just the learning and teaching. However, for the purpose of this paper, I am focussing exclusively on the aspects of these two roles that pertain to the learning and teaching relationship between the two entities. This is because it is this aspect that has been at the forefront of the discussion about 'students as consumers', and about which there is such unease.

\section{Consumerist models}

Although the concept of 'students as consumers' is not new, most of the scholarly papers ${ }^{5}$ on this issue are based in the US (for example: Delucchi and Smith 1997, Shepperd 1997, Delucchi and Korgen 2002). The main problem appears to be that the consumer model can create "an adversarial or competitive relationship" (Shepperd 1997, p335) within what should be more of a collaborative learning relationship. Delucchi and Korgen (2002) criticise the dominance of the market economy in education, and claim that it is leading to an increased disengagement by students. Their study indicates one of the main problems is a mismatch between what students feel they are buying (as consumers) and what their lecturers feel they are selling. Over $40 \%$ of their student sample believed that paying tuition fees equated to buying a degree. Their results indicate that 'students as consumers' do not recognise the need to invest sufficiently in their own education. Whilst Delucchi and Korgen (2002), and others, recognise the benefits of a consumer approach to the facilities side of HE in improving the conditions for students, the problem with a consumer approach for the learning and teaching

\footnotetext{
${ }^{4}$ Which was not specifically made by Hardimon himself.

${ }^{5}$ As opposed to discussion or comment papers.
} 
relationship is that "the teacher-student relationship is not intrinsically economic" (p106).

Shepperd (1997, p334) argues that a "professional/client model" is an improvement on a straight consumer model. However, he argues that it is still difficult to keep education as the focus as the boundaries blur between student qua learner and student qua client. Shepperd (1997) goes on to advocate a partnership model where both partners are engaged in the process of learning. Whilst I agree, it is not clear how this differs to what should have been the status quo or how the trend to consumerism can be tackled. Naidoo and Jamieson (2005, p271), discussing the emerging consumerism in the UK, claim that the "previously integrated relationships between academics and students are likely to become disengaged" in a consumer model of HE. Naidoo and Jamieson (2005), whilst acknowledging the paucity of empirical evidence in this area, claim that the biggest danger of a consumer model is the impact on the learning and teaching relationship. They point out that the evidence to date suggests 'students as consumers' become increasingly disengaged and passive, demonstrating a lack of responsibility for their role in the learning process. In other words, learners have lost sight of the function of a student qua learner, rather than as a consumer. If they don't identify with the role of a learner, they will not be aware of the moral obligations derived from that role. This is why I will argue that, within the learning and teaching relationship, we need an alternative to the consumer model.

\section{Moral Role Obligations}

Hardimon (1994, p334) defines the term role obligation as "a moral requirement, which attaches to an institutional role, whose content is fixed by the 
function of the role, and whose normative force flows from the role." In other words, the function of a learner and that of a lecturer, give rise to obligations, which persons fulfilling those functions ought to fulfil.

Hardimon (1994) refers to the moral role obligations attached to formal roles, such as those we are examining, as contractual role obligations ${ }^{6}$. He claims there are two key characteristics that define these role obligations, namely, voluntary acceptance and role identification.

\section{Voluntary acceptance}

In order to be morally obligated to undertake the function assigned to the institutional role of learner or lecturer, the person must voluntarily consent to undertake that role. This is an important aspect of role obligations because one cannot judge the conduct of an individual against a normative framework attached to a role, if the person has not voluntarily accepted that role. If I did not voluntarily accept the role of lecturer, then I cannot be expected to view myself as being morally obliged to do what lecturers ought to do. Let us assume, for the purpose of this paper, that both lecturers and learners have voluntarily accepted their roles.

\section{Role identification}

The issue of role identification is a little more complex. Hardimon (1994) argues that not only must a person voluntarily accept the role and its obligations but they must identify with that role.

"To identify with a role is

I. To occupy the role;

II. To recognize that one occupies the role;

III. To conceive of oneself as someone for whom the norms of the role function as reasons."

(Hardimon, 1994, p358)

\footnotetext{
${ }^{6}$ Despite the term, Hardimon is not discussing legal role obligations.
} 
The first two conditions of role identification are self-explanatory. For example, one must actually be a learner (or lecturer) and recognise oneself as a learner (or lecturer) if the third condition is to have meaning. The third condition is best described by Hardimon himself in his example of a judge

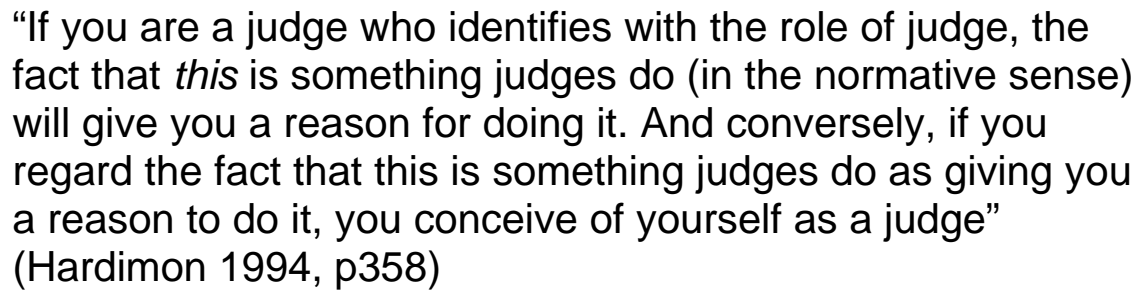

The function of a judge not only describes the purpose of that role, but also provides a normative framework for what a judge ought to do in order to fulfil this function, with the excellence proper to it. If one perceives oneself as occupying the role of judge, then doing what a judge ought to do provides reasoning for actions taken in pursuit of being an excellent example of a judge. However, Hardimon's position is weak if he is viewing this as a necessary condition of role obligation, as he appears to give permission for one to exclude oneself from role obligations if one does not identify oneself with that role. I consider that the necessary and sufficient conditions for being subject to role obligations are much simpler than Hardimon portrays. These are simply that

I. The individual occupies the role

II. The individual voluntarily accepted the role, satisfying the conditions of informed consent to do so.

The second and third conditions of Hardimon's role identification illustrate two possible reasons why people may not perceive the need to fulfil their role obligations. 
However, these are not necessary conditions for the role obligations to apply. For example, learners may only identify with their role of consumer and judge their actions pertaining to fulfilling only that role. However, they cannot avoid the role obligations derived from the role of learner, if they are voluntarily occupying that role. Whilst it may help us to understand why they fail to identify with their role as learner, it is not a reason to dismiss their obligations.

In my account of role obligations, individuals who occupy an institutional role, and who fail to fulfil the function of that role, can be judged as failing or deficient, relative to the normative framework derived from the function of that role. In Hardimon's account, individuals who do not identify with their institutional role cannot be judged in relation to such a framework. For example, a lecturer who is teaching or facilitating a learner in higher education, cannot simply avoid his role obligations purely because he does not view himself as subject to the norms of the role function. I have met lecturers who consider themselves to be primarily researchers, even though they are involved in teaching learners. As such, by Hardimon's criteria, they may choose not to fulfil their role obligations as lecturers ${ }^{7}$. This would not be acceptable in the learning and teaching relationship, which is why I have strengthened the position for my account of role obligations.

\section{The Function of Learners and Lecturers}

I have argued above that the role obligations attached to a defined role are derived from the function of the role being voluntarily occupied. It is now necessary to defend my claim that the function of an entity ${ }^{8}$ has both a descriptive and a

\footnotetext{
${ }^{7}$ In the learning and teaching aspect of that role, which is the focus of this paper.

8 The term 'entity' refers to a specific institutional role in this case
} 
normative purpose. It is necessary to demonstrate this in order to support the claim that the function of an entity can give rise to moral obligations. In order to do this, I propose to use the 'function argument' from Aristotle's Nichomachean Ethics (Book One). ${ }^{9}$ In doing so, I am aware of exposing myself to difficulties, given the many philosophical challenges this argument presents. However, it is not the purpose of this paper to defend the position, or resolve the difficulties in Aristotle's claim. I intend only to take what I need from the argument to substantiate my claim that there are central functions of both a learner and a lecturer, which define the normative position of what they ought to do. The function argument seems eminently suited to this role, for as Megone (1998, p192) argues: "if we can determine the function or purpose of a thing, then we can determine the good of a thing of that kind". Therefore, if we can determine the function of the learner and lecturer roles, we can then determine what the individuals who occupy these roles ought to do.

\section{Brief outline of the function argument}

Aristotle's Nichomachean Ethics (Book One) begins by claiming there is one supreme good, which constitutes the essence of a good life, and to which all other goods merely contribute. Having made a claim that there is a supreme good, Aristotle goes on to define what this is. He begins by arguing that the supreme good is what could be called 'happiness'. However, he is not content to leave this term loosely defined, but he wants to "try to describe at least in outline" (NE Bk1 1094a 25), what happiness really is. Lawrence (2006) explains that the role of the function argument is to elucidate eudaimonia: we can see better what constitutes a wonderful life, by looking at what it is 'to live' (that is, to function as a human being). The definition of happiness lies in determining the purpose of all actions. If we know what

\footnotetext{
${ }^{9}$ Unless otherwise stated, I have used the Penguin Classics version translated by JAK Thomson - see bibliography for full details
} 
our function is, then this in itself will tell us what happiness is, that which defines the purpose of our actions. The purpose of our actions is to fulfil our function well, since to do so will bring us the greatest happiness.

Although Aristotle is seeking to elucidate the meaning of a human life, the function argument could be said to originate from observation of how other 'things' function and what role the function of a 'thing' plays in determining its goodness. This function both defines the very essence of what that thing is, and provides a normative measure for judging the "goodness" (NE Bk1 1097b 27) of that thing ${ }^{10}$. It is this normative part of the function argument that I am concerned with in this paper. Learners and lecturers can achieve the ultimate 'good' if they fulfil their functions and, of course, the role obligations derived from each function.

There are three important aspects to the function argument that allow for a triangulation of sorts, namely, the essence of an entity, its function and the goodness of that entity. The example of a knife is sometimes used to illustrate this teleological relationship. The function of a knife is to cut, because it is in essence a sharp cutting device. The best state for a knife is for it to be cutting well, because that is what knives exist for, and they must be sharp to fulfil their function. The normative aspect of the function argument differentiates between merely fulfilling the function, and doing it well. A blunt knife will cut (after a fashion) but a sharp knife will cut well. In Aristotle's normative function argument, the blunt knife is a bad or defective knife and the sharp knife is a good knife. The 'ultimate good' or the 'chief happiness' for a knife is to be a sharp knife that cuts well. A knife will have a wonderful life (as lives of knives go), if it is cutting well. This is what its purpose is (its reason for being) and this is also how we judge if it is a good knife. So for Aristotle, the function of an entity

\footnotetext{
${ }^{10}$ In the Dover publication of NE (Kaufman 1998) the term 'excellence' is used rather than 'goodness'.
} 
is derived entirely from the essence of what it is to be that entity. The function of a lecturer or learner is derived from the essence of what those entities exist for. ${ }^{11}$

Although this has been a necessarily brief outline which cannot hope to do justice to Aristotle's function argument, hopefully, it will be sufficient for me to defend my claim that the role obligations of lecturers and learners are derived from the function of each of these roles.

\section{The function argument applied to the role of lecturer and learner}

Definitions of the lecturer and learner roles are necessarily broad at this stage and I acknowledge that further work is needed in this area. This is not intended to be an operational definition of specific activities performed by lecturers, but rather it is a definition aimed at describing the essence of this role in relation to the learner. For the purpose of this paper I should like to make the claim that the function of lecturers is to use their professional knowledge and skills, in order to take actions which could reasonably ${ }^{12}$ be expected to facilitate learning for all learners with whom they have a learning and teaching relationship. A person fulfilling this function may also have other functions, such as that of researcher. These additional functions will give rise to their own role obligations. The issue of conflicting role obligations is the focus of a future paper and will not be addressed here. My concern here is with the obligations of the lecturer, qua teacher.

The normative role of the function argument means that individuals occupying the role of lecturer in higher education ought not to take any actions which are not aimed at fulfilling this function. If a lecturer fulfils all aspects of his or her role well, he

\footnotetext{
${ }^{11}$ But in this case focussing on what they exist for in the learning and teaching context.

12 That is, that any reasoning person would agree were likely to facilitate learning. By 'reasoning person' I am referring to people who reason before making a decision or arriving at an opinion.
} 
or she could not be viewed as failing, or being deficient, in fulfilling the moral obligations of the role they occupy.

Again, for the purpose of this paper, I am making the claim that the function of learners in higher education is to participate fully with all aspects of their learning, to the best of their abilities. In the same way as I argued above, the learner who wants to fulfil his or her function well must only take actions consistent with this function. If the learner takes actions not consistent with the function, he or she can be deemed to be failing or deficient in fulfilling their function.

\section{Role Obligations Strengthening the Normative Aspect of the Function Argument}

Aristotle is not claiming that "all intentional action aims at some good" (Lawrence 2006, p42), but only those actions taken deliberately towards achieving the ultimate good of fulfilling one's function well. Aristotle is not claiming that all humans will always reason because everything they do in life will be aimed at the 'chief good'. All he is saying is that humans will strive to fulfil their function of reasoning well if the purpose of their action is to work towards the wonderful life. However, this condition leaves scope for actions taken for other purposes. Other such purposes might be, for example, the lecturer who cancels all his teaching because he wants to spend that time putting together a research bid, or the student who fails to prepare for classes because he wants to be the best partygoer. These role holders are not aiming at being excellent examples of lecturer and learner in order to achieve the greatest 'good' accorded to those functions. The concept of moral role obligations, discussed in an earlier section, strengthens this normative aspect of the function argument. The moral role obligations, derived from the functions of the lecturer and learner, oblige those who are voluntarily occupying these roles to only take actions consistent with the learner or lecturer function. If they 
take actions which are not consistent with the role they voluntarily occupy, they can be considered as failing or being deficient in their moral obligations.

Perhaps one of the most positive aspects of this current focus on what the lecturer is morally obliged to do for the learner, is that Universities will be under closer scrutiny of their actions to deal with failing or defective lecturers ${ }^{13}$. The student who fails to fulfil their moral role obligations, derived from their function as learner, sees the result of their deficiency in their assessment marks and degree classification. Many of us may remember lecturers who were not fulfilling their function well, for whom there were no consequences. As a result of the pendulum swinging the other way, this is no longer tolerated by learners. Of course, learners need to have a clear understanding of what the function of a lecturer is if they are to make reasonable claims of failure or deficiency.

It is important to remember that the learner cannot demand that the lecturer take actions which are not consistent with the function and the role obligations derived from it. Students cannot demand a degree, regardless of their learning, merely because they now pay directly. Such a demand is not consistent with the function to facilitate learning and the lecturer is not obliged to acquiesce to such a demand.

\section{Conclusions and implications for Practice}

My claim that lecturers and learners have moral obligations to one another, derived from their functions, is not affected by the introduction of higher tuition fees. Those moral obligations would be there regardless of fees charged. But what has changed is that attention is focussed on what the lecturer is obliged to do for the

\footnotetext{
${ }^{13}$ That is those not fulfilling their function well.
} 
learner, particularly in the context of learning and teaching. This attention might be perceived as arising from students paying higher fees but I have shown there is a more fundamental source for the obligations of lecturers to learners, which may sit more comfortably with our view of education. Unfortunately, there is little current attention given to what the learner is obliged to do. This is the big gap in the current conversation and one that needs addressing if a reasonable balance is to be reached.

The main implication for practice is to ensure that the attention is given to the moral obligations of both entities. The structure for higher education funding is, in the opinion of many, a misguided policy. The notion of learner as consumer is being pedalled by the government of the day but there is no reason why we, as practitioners, cannot frame our learning and teaching relationship in another way.

We now need to engage students in reflecting on ways in which they can fulfil their role obligations as learners, as well as articulating more effectively our own role obligations and how we will fulfil them. Their role as a learner in higher education places upon them a moral obligation to fulfil their function well, as does our own. We need to use effective language to articulate the obligations of both parties. As lecturers, a change in the funding structure does not provide an extra moral role obligation, but we may need to be clearer about the reasoning behind this to our students. Possibly, in the past, the focus may have been more on the obligations for the students because the 'tax payer' was paying for their higher education and the students would reap the benefits in the future. Now they are paying directly and the benefits are much less certain, the pendulum is swinging the other way. It is now incumbent upon practitioners to take a lead in this debate, rather than leaving it to the politicians. We need to restore the balance in reviewing, discussing and gaining 
consensus on the role obligations of both parties. Whilst I have made a tentative start in defining the function of these entities, this is only the beginning which, I hope, will prompt wide discussion.

Many Universities use a 'student contract' to articulate these obligations but using legal and/or contractual language may perpetuate some of the problems anticipated with a consumer approach. However, the existence of a written document, outlining the moral obligations of both parties to the learning relationship, would make a helpful platform for conversations about this with our students; providing it is written in accessible language and is 'owned' by both students and staff.

On a practical level, role obligations of both parties, can provide a useful platform for discussions on ground rules for group teaching and learning situations, as well as one to one learning and teaching relationships. Asking students to articulate to one another (as well as us) what they consider their function as a learner entails can lead nicely into discussions on the nature and skills of effective learning. Likewise, discussing what learners consider the function of a lecturer to be, in the learning and teaching relationship, can raise awareness of unreasonable or misguided expectations. Reminding learners throughout the module of what was discussed may facilitate on-going evaluation of how effectively both parties are fulfilling their role obligations. Making reference to the role obligations in end-ofmodule evaluation surveys may prompt the learner to reflect on how effectively they have contributed to the learning and teaching process, rather than focusing exclusively on how well the lecturer has done; which is often the case.

From the preceding discussion, I can conclude that learners and lecturers both have role obligations within the learning and teaching relationship. These role 
obligations are derived from the functions of the roles that are voluntarily held by each party in that relationship. Using Aristotle's function argument, I have shown that by ascertaining the respective functions of a learner and a lecturer, both descriptive and normative frameworks are revealed. The normative purpose is strengthened by articulation of the moral role obligations prior to, and during, the term of the learning and teaching relationship. I have suggested that viewing the obligations each party has to one another, within a framework of moral role obligations, would produce a more balanced, and less uncomfortable, position than that of a consumerist model.

\section{References}

Aristotle The Nicomachean Ethics. Translated by JAK Thomson (2004) $3^{\text {rd }}$ Edition. London: Penguin Books Ltd.

Broadie S (1991) Ethics with Aristotle. New York: Oxford University Press

Evans J (2007) Teaching and learning for customer satisfaction in higher education. The International Journal of Learning. Vol. 14(1), p191-208

Delucchi M and Korgen K (2002) "We're the customer - we pay the tuition": student consumerism among undergraduate sociology majors. Teaching Sociology. Vol 30, p100-107

Delucchi M and Smith W L (1997) A postmodern explanation of student consumerism in higher education. Teaching Sociology. Vol. 25, p322-327

Hardimon M O (1994) Role Obligations. The Journal of Philosophy. Vol xci (7), p333363

Jones G (2010) Managing student expectations: the impact of top-up tuition fees. Perspectives: Policy and Practice in Higher Education. Vol 14(2), p44-48 
Lawrence G (2006) Human good and human function in Kraut R (Ed) The Blackwell's Guide to Aristotle's Nichomachean Ethics. Oxford: Blackwell Publishing

Melear K B (2003) From In Loco Parentis to consumerism: a legal analysis of the contractual relationship between institution and student. NASPA Journal. Vol 40 (4), p124-148.

Megone C (1990) The quality of life: starting from Aristotle. Chapter 2 in Baldwin S, Godfrey C and Propper C (1990) Quality of Life: Perspectives and Policies. London: Routeledge

Megone C (1998) Aristotle's function argument and the concept of mental illness. Philosophy, Psychiatry and Psychology. Vol. 5 (3), p187-191

Naidoo R and Jamieson I (2005) Empowering participants or corroding learning? Towards a research agenda on the impact of student consumerism in higher education. Journal of Education Policy. Vol. 20 (3), p267-281

O'Neill P B (2010) The first week: engaging students and creating expectations. College Teaching. Vol 58, p69

Ramsden P (2008) The Future of Higher Education: teaching and the student $\begin{array}{lll}\text { experience. } & \text { Accessed from }\end{array}$ http://www.bis.gov.uk/assets/BIScore/corporate/docs/H/he-debate-ramsden/pdf on 28.09.10

Shepperd J W (1997) relevance and responsibility: a postmodern response. Response to "A postmodern explanation of student consumerism in higher education". Teaching Sociology. Vol 25, p333-335 
